\title{
Long-term medication in depot clinics and patients' rights: an issue for assertive outreach
}

\author{
Nigel Eastwood and Robert Pugh
}

\begin{abstract}
This study investigated the knowledge and attitude of 100 patients about their depot neuroleptic medication. Patients were well informed about their medication, particularty those seen in depot clinics. Most patients were content with service dellvery but $\mathbf{4 8 \%}$ did not reallse that they had a choice about recelving their treatment. This aspect of patients' rights should be addressed and demands sensittve manogement in the case of depot refusers, or when assertive outreach is planned. We suggest that such isures should be incorporated into an ectucational programme and discussed with patients when they are relatively well.
\end{abstract}

Depot neuroleptic medication is the main form of prophylactic treatment for schizophrenia and related psychotic illnesses. Although there is a great deal of research on the efficiency of these drugs, there has been less work on the way they are administered; but there is little value in having an effective treatment if it is not reliably taken. In the community, it both reduces relapse rates (Gilbert et al, 1995) and is cost-effective (Hale \& Wood, 1996). 'Depots' may be administered in a variety of settings including depot clinics. Research suggests that the majority of patients prefer depot clinics (Singh et al, 1995) although in Singh et als study, 25\% of attenders would have preferred alternative arrangements.

To our knowledge, there have been no studies which have specifically investigated the proportion of patients that know that they may refuse their depot medication if they wish, although a recent review article by Brabbins et al (1996) covers the medico-legal framework of consent to neuroleptic medication. Guidance is given in the Code of Practice (Department of Health and the Welsh Office, 1993) about the issue of withdrawing consent to treatment; however, there is no mention in the proposed Mental Health Services Patients' Charter (Department of Health, 1996).

This study set out to explore the following issues: (1) what knowledge do patients have about their depots, including their rights to refuse? (2) Are patients satisfied about the administration of their injection?

\section{The study}

\section{Procedure}

One hundred patients who were prescribed depot neuroleptics were interviewed by N.E. and a semi-structured depot neuroleptic interview was completed in each case. Patlents receiving depots were identified from various settings within the Norwich, Bury St Edmunds, and Cambridge catchment areas. Verbatim recordings of patients' replies were taken and a second psychiatric assessor made independent ratings of patients' responses.

\section{Subjects}

Patients were receiving treatment in the following catchment areas: Norwich $(69 \%)$, Bury St Edmunds (20\%) and Cambridge (11\%). Most (86\%) were out-patients, and all were informal at the time of interview. Patients were interviewed in a variety of settings including depot clinics, day centres, wards, hostels, out-patient clinics, and other forms of accommodation. None were recelving compulsory treatment under the Mental Health Act 1983.

\section{Methods and measures}

The interview comprised two main parts:

(1) Information. This assessed the knowledge that patients had about their depots. including type, dose, frequency, when next due, and side-effects. They were also asked if they believed they could refuse treatment if they wished.

(2) Patient satisfaction. The following were established: who gives depot, administrator's gender, and the setting in which the injection is given, compared with what the patient would prefer. Patients were asked whether they preferred intramuscular or oral medication, why they thought the depot was being given, and whether they believed that the depot was helping them.

Data were analysed using SPSS software. 
Table 1. Patients' knowledge of their depot medication

\begin{tabular}{lllll}
\hline & \multicolumn{4}{l}{ Percentage of correct answers about depots } \\
\cline { 2 - 5 } Location of depot administration & Type & Dose & Frequency & Next due \\
\hline Day centre & 93 & 73 & 100 & 60 \\
Depot clinic & 87 & 81 & 96 & 96 \\
Hostel & 57 & 57 & 100 & 100 \\
Home & 82 & 55 & 91 & 82 \\
Ward & 64 & 29 & 86 & 43 \\
\hline
\end{tabular}

\section{Findings}

The patients

Overall the mean age was 44 years (s.d.=11.4; range 19-66). Sixty-five per cent of the sample were male with a mean age of 42.9 years (s.d.=12.0) and the mean age of the females was 46.2 years (s.d.=10.0).

\section{Information about depots}

The majority of patients (82\%) correctly knew the name of their depot, $68 \%$ knew the correct dose, $95 \%$ knew the frequency of the injection, and $82 \%$ could say when their depot was next due. Table 1 shows that knowledge of type of depot and its dose was better in those receiving their depot in a depot clinic or day centre than in the other settings. Poor knowledge on the wards probably reflected a more unwell subgroup.

Eighty-eight per cent of patients were able to supply an appropriate explanation for why they were being prescribed a depot. When patients were asked about what side-effects they experienced, $41 \%$ admitted to no side-effects, $34 \%$ named one side-effect, $15 \%$ two, $6 \%$ three, $2 \%$ four, and $1 \%$ five and six respectively.

Patients were asked whether they thought they had a choice in receiving a depot; only $52 \%$ were clear that they did have a right to refuse. A larger proportion of those in the depot clinics knew they had a choice although this did not reach clinical

Table 2. Do patients believe they have the right to refuse depot?

\begin{tabular}{llll}
\hline & \multicolumn{2}{c}{ Right to refuse depot? } \\
\cline { 2 - 4 } Location of depot injection & Yes & $\begin{array}{c}\text { Don't } \\
\text { know }\end{array}$ & No \\
\hline Depot clinic & 33 & 5 & 15 \\
Day centre & 7 & 1 & 7 \\
Hostel & 3 & 1 & 3 \\
Home & 5 & 0 & 6 \\
Ward & 4 & 0 & 10 \\
Total & 52 & 7 & 41 \\
\hline
\end{tabular}

significance. The distribution of replies by location is shown in Table 2.

\section{Attitudes towards depot}

All depots were given either by CPNs or other nurses. Most patients (99\%) were happy with who gave their depot, with $63 \%$ declaring no preference. Of the nurses $61 \%$ were female; $73 \%$ of patients had no preference about the gender of the nurse, but $7 \%$ of patients (five male, two female) would have preferred a nurse of a different gender, usually a female instead of a male.

Table 3 shows where depots were given. Overall, the majority $(93 \%)$ of patients were happy with their arrangement with $38 \%$ not minding about the location. A third of patients would prefer to be receiving oral medication instead of an injection, with the remainder preferring the depot $(53 \%)$ or citing no preference $(14 \%)$. Of those wishing to change, half recognised that they have a choice.

When asked about the benefits of a depot, $54 \%$ considered that it helped, $26 \%$ thought it was of some use, $18 \%$ thought it provided no benefit, and $2 \%$ were uncertain.

\section{Comment}

General aspects of depot administration satisfactory

Patients in this study were generally well informed about the nature of their depot treatment; this was particularly the case in depot clinics and day centres. Most patients were content with service

Table 3. Percentage distribution of locations for depot injections

\begin{tabular}{lc}
\hline Location of depot administration & $\%$ \\
\hline Depot clinic & 53 \\
Day centre & 15 \\
Ward & 14 \\
Home & 11 \\
Hostel & 7 \\
\hline
\end{tabular}


delivery although a third of patients would have preferred to take only oral medication.

Fewer side-effects than expected were reported, $41 \%$ of patients considering that they had no symptoms.

\section{Study revealed an unawareness about rights to refuse treatment}

Nearly half of those interviewed were unclear as to whether they had a choice about receiving the injection. Patients attending depot clinics were better informed about their rights whereas 10 out of the 14 in-patients, all informal, thought the depot was compulsory.

\section{Assertive outreach is vital but patients also need to be aware of rights}

The conceptual model of a comprehensive community-based programme for patients with chronic mental illnesses first developed by Stein \& Test (1980), with its emphasis on assertive outreach, has been shown to have clear benefits for the patients and their carers (Burns \& Santos, 1995). A component of the work of mental health staff in the community is to maximise patients' compliance with medication, although education plays an unclear role (Macpherson et al, 1996). In this study, both patients' information about their drugs and the administration of depots appear to have been successful, but the lack of patients' knowledge about their rights is a serious cause of concern. All those receiving depots must be properly informed. This should be done at an early stage and the disadvantages of patients discontinuing their treatment discussed with them when they are relatively well. Information about 'rights' could also be incorporated into Patient Information Leaflets.

\section{Acknowledgements}

We thank Shirley Pearce (Professor of Clinical Psychology, University of East Anglia) and Steve Bazire (Principal Pharmacist, Norfolk Mental Health Care and Learning Disabilities) for their helpful comments on this study.

\section{References}

Brabbins, C., Butler, J. \& Bentall. R. (1996) Consent to neuroleptic medication for schizophrenia: clinical, ethical and legal issues. British Journal of Psychiatry. 168, 540-544.

BURNS, B. J. \& SANTOS, A. B. (1995) Assertive community treatment: an update of randomised trials. Psychiatric Services, 46, 669-675.

DEPARTMENT OF HEALTH AND THE WELSH OFFICE (1993) Mental Health Act 1983 Code of Practice. London: HMSO.

Department of HEALTH (1996) Mental Health Services: The Patients' Charter (Consultation Edition). London: HMSO.

GILBERT, P. L.. HARRIS, M. J.. MCADAMS, L. A., et al (1995) Neuroleptic withdrawal in schizophrenic patients; a review of the literature. Archives of General Psychiatry. 52, 173-188.

HALE, A. S. \& WOOD, C. (1996) Comparison of direct treatment costs for schizophrenia using oral or depot neuroleptics: a pharmacoeconomic analysis. British Journal of Medical Economics, 10, 37-45.

MACPHERSON, R., JERROM, B. \& HUGHES, A. (1996) A controlled study of education about drug treatment in schizophrenia. British Journal of Psychiatry, 168, 709 717.

Singh, V., Hughes, G. \& GoH, S. E. (1995) Depot clinic: consumers' viewpoint. Psychiatric Bulletin, 19, 728730.

Stein. L. I. \& TEST, M. A. (1980) Alternative to mental hospital treatment: I. Conceptual model, treatment programme, and clinical evaluation. Archives of General Psychiatry. 37, 392-397.

Nigel Eastwood, Senior Registrar, and Robert Pugh, Consultant in Rehabilitation Psychiatry, Norfolk Mental Health Care NHS Trust, Hellesdon Hospital, Drayton High Road, Norwich NR6 5BE

*Correspondence 